\title{
AGE AND GENDER DIFFERENCES IN PREVALENCE OF SCREEN BASED BEHAVIOUR, PHYSICAL ACTIVITY AND HEALTH COMPLAINTS AMONG SLOVAK SCHOOL-AGED CHILDREN
}

\author{
Daniela Husárová1, Zuzana Dankulincová Veselská1, Dagmar Sigmundová2, Andrea Madarasová Gecková1,3 \\ 'Department of Health Psychology, Faculty of Medicine, P. J. Šafárik University in Košice, Košice, Slovak Republic \\ ${ }^{2}$ Centre for Kinanthropology Research, Institute of Active Lifestyle, Faculty of Physical Culture, Palacký University Olomouc, Olomouc, Czech \\ Republic \\ ${ }^{3}$ Olomouc University Social Health Institute, Palacký University Olomouc, Olomouc, Czech Republic
}

\section{SUMMARY}

Aim: The aim of this study was to assess age and gender differences in prevalence of screen based behaviour, physical activity and health complaints among Slovak school-aged children.

Methods: Data from the cross-sectional Health Behaviour of School-aged Children study collected in 2010 among Slovak children (age 11-15 years, $N=8,042$ ) was used. Logistic regression models adjusted to age and gender were used to analyse the associations between watching TV, working with a computer or playing computer games and physical activity and headache, backache, sleep difficulties, feeling low, irritability, and feeling nervous.

Results: Around one-quarter of adolescents is spending more than three hours a day with screen-based activities. While the age was significantly associated with watching TV and computer use, gender was significantly associated only with excessive computer use. As for physical activity, only $25 \%$ of adolescents reported being physically active every day as recommended, and this number decreases with increasing age. Boys used to be more often active in comparison with girls. A sizeable number of adolescents suffer with selected health complaints every week. Moreover, the prevalence of health complaints increases with age and is significantly higher among girls.

Conclusions: The prevalence of screen-based activities as well as insufficient physical activity and health complaints among adolescents is relatively high and it increases with age. Gender differences are also significant, except for watching TV.

Key words: watching TV, computer use, psychological complaints, physical complaints, adolescence

Address for correspondence: D. Husárová, Department of Health Psychology, Faculty of Medicine, P. J. Šafárik University in Košice, Trieda SNP 1, 040 01, Košice, Slovak Republic. E-mail: daniela.brindova@upjs.sk

\section{INTRODUCTION}

More and more children are spending too much of their free time watching TV, playing PC games or using the Internet at the expense of physical activity (1) and this behaviour has many negative effects on adolescents' health. A high level of screenbased sedentary behaviour is related to different kind of physical problems $(2,3)$ or psychological complaints (4). According to findings of the international Health Behaviour in School-aged Children (HBSC) study, age differences were observed. Around $63 \%$ of 15 year olds spend their free time watching TV, in case of 11 year olds it is $56 \%$. As for gender differences, they were not large. Among 15 year olds $64 \%$ of boys and $62 \%$ of girls watch TV for two or more hours on weekdays. As for 11 year olds, $58 \%$ of boys and $54 \%$ of girls spend their time watching TV (5).

Positive benefits of regular physical activity, including positive effect on mental and physical health, are generally known $(1,6$, 7). However, research suggests that many children do not reach recommended levels of physical activity (8-10). Furthermore, the findings indicate that level of physical activity significantly decreases with age in both girls and boys $(11,12)$. Overall, $15 \%$ of 15 year olds reported at least one hour a day spent in physical activity in comparison with $23 \%$ of 11 year olds (5). In connection with gender differences, boys are more physically active in comparison with girls (13) and spend 18 and 13 minutes more per day in moderate to vigorous physical activity on weekdays and weekends, respectively (14).

Negative trends were also observed in prevalence of health complaints. The data showed that sizeable number of adolescents suffered subjective recurrent health complaints (15) and 4 of 10 adolescents weekly experienced multisite pain (16). Furthermore, findings indicate that girls experienced various pain types more frequently than boys and the prevalence of pain significantly increases with age in both (17).

The interest in sedentary behaviour, physical activity as well as health is still growing (17-20), but there are only few studies reporting findings from Central European countries $(21,22)$. However, in these countries, including Slovakia, are observed negative trends of lifestyle among adolescents in terms of increasing sedentary behaviour at the expense of physical activity and health complaints in comparison with other countries in Europe $(23,24)$. Understanding actual situation in these countries could 
provide important information for future interventions and programmes supporting healthy life.

Therefore, the aim of this study was to investigate the prevalence of physical activity, screen-based behaviour and subjective health complaints as well as possible age and gender differences among school-aged children in Slovakia.

\section{MATERIALS AND METHODS}

\section{Sample and Procedure}

We used data from the HBSC study conducted in May-June 2010 in Slovakia. From a list of schools based on information from the Slovak Institute of Information and Prognosis for Education, 134 larger and smaller schools located in rural as well as in urban areas from all regions of Slovakia were randomly chosen to create a representative sample. We contacted 108 schools, and 106 schools took part in our survey, representing 98.1\% school response rate. According to the protocol of the HBSC study, classes from the 5 th to 9 th grades were selected randomly, one from each grade per school. We obtained data from 8,491 adolescents from the 5 th to 9 th grade of elementary school in Slovakia (response rate $79.5 \%)$. Non-response was primarily due to illness $(10.3 \%)$ and parental disapproval of the participation of their children (7.4\%). We decided to exclude children under 11 and over 15 years of age to make the sample more homogeneous and to avoid the influence of age extremes. After this step, the study sample consisted of 8,042 adolescents (mean age 13.13 years, $48.6 \%$ of boys) from elementary schools in Slovakia.

The study was approved by the Ethics Committee of the Faculty of Medicine at P. J. Šafárik University in Košice. Parents were informed about the study through the school administration and could opt out if they disagreed with it. Participation in the study was fully voluntary and anonymous, with no explicit incentives provided for participation. Questionnaires were administrated by trained research assistants in the absence of a teacher during regular class time.

\section{Measures}

Physical activity was measured by an item asking adolescents about the number of days over the past week that they were physically active for a total of at least 60 minutes per day. The question was preceded by explanatory text that defined moderateto-vigorous activity as "any activity that increases your heart rate and makes you get out of breath some of the time", offering examples of such activities (running, inline skating, cycling, dancing, swimming, ice skating etc.) (5). Responses were in a range from 0 days to 7 days, and according to the WHO recommendation (25) were classified into three categories as follows: 1 - active less than 2 days; 2 - active at least 3 days; 3 - active every day. Regarding to validity, authors concluded that moderate to vigorous physical activity (MVPA) index has acceptable validity for measuring amount of physical activity in adolescents (26-28).

Screen-based activities represented by watching TV, playing computer games and using the Internet were assessed by three separate items. Watching TV was measured by the question: "About how many hours a day do you usually watch television (including videos) in your free time?" Computer gaming was measured by asking: "About how many hours a day do you play PC-games or TV-games (PlayStation, Xbox, GameCube etc.) in your free time?" Computer use was measured by asking: "About how many hours do you spend using a computer (Internet, chatting, e-mailing, homework etc.)?" All questions had the same nine responses categories separately for weekdays and weekends: None at all; About half an hour a day; About 1 hour a day; About 2 hours a day; About 3 hours a day; About 4 hours a day; About 5 hours a day; About 6 hours a day; About 7 or more hours a day (3). Using the recommendations of the American Academy of Pediatrics (29) they were classified into three categories as follows: 1 - active less than 2 hours per day; 2 - active $2-3$ hours per day; 3 - active more than 3 hours per day.

The HBSC-symptoms checklist (HBSC-SCL) assessed the occurrence of eight subjective physical and psychological health complaints. Participants indicated how frequently during the last 6 months they had each of eight symptoms, namely headache, stomachache, backache, feeling low, irritability and bad temper,

Table 1. Descriptive characteristics of the sample, Health Behaviour in School-aged Children study collected in Slovakia in 2010

\begin{tabular}{|c|c|c|}
\hline & & $\mathrm{n}(\%)$ \\
\hline \multirow[t]{2}{*}{ Gender } & boys & $3,910(48.6)$ \\
\hline & girls & $4,132(51.4)$ \\
\hline \multirow[t]{5}{*}{ Age } & 11 years old & $1,259(15.7)$ \\
\hline & 12 years old & $1,535(19.1)$ \\
\hline & 13 years old & $1,746(21.7)$ \\
\hline & 14 years old & $1,897(23.6)$ \\
\hline & 15 years old & $1,605(20.0)$ \\
\hline \multirow[t]{2}{*}{ Headache } & every week and more & $2,828(33.8)$ \\
\hline & less than every week & $5,541(66.2)$ \\
\hline \multirow[t]{2}{*}{ Backache } & every week and more & $1,868(22.5)$ \\
\hline & less than every week & $6,424(77.5)$ \\
\hline \multirow[t]{2}{*}{ Sleeping difficulties } & every week and more & $1,906(23.0)$ \\
\hline & less than every week & $6,382(77.0)$ \\
\hline \multirow[t]{2}{*}{ Feeling low } & every week and more & $2,723(32.7)$ \\
\hline & less than every week & $5,593(67.3)$ \\
\hline \multirow[t]{2}{*}{ Irritability } & every week and more & $4,000(48.1)$ \\
\hline & less than every week & $4,310(51.9)$ \\
\hline \multirow[t]{2}{*}{ Feeling nervous } & every week and more & $3,783(45.5)$ \\
\hline & less than every week & $4,537(54.5)$ \\
\hline \multirow[t]{3}{*}{ Watching TV } & less than 2 hours & $1,919(28.3)$ \\
\hline & 2-3 hours & $3,347(49.4)$ \\
\hline & more than 3 hours & $1,503(22.2)$ \\
\hline \multirow{3}{*}{$\begin{array}{l}\text { Working with a PC or } \\
\text { playing PC games }\end{array}$} & less than 2 hours & $2,574(36.3)$ \\
\hline & $2-3$ hours & $2,882(40.6)$ \\
\hline & more than 3 hours & $1,640(23.1)$ \\
\hline \multirow[t]{3}{*}{ Being physically active } & every day (recommended) & $1,807(25.1)$ \\
\hline & $3-6$ days & $3,449(47.9)$ \\
\hline & 2 days or less & $1,945(27.0)$ \\
\hline
\end{tabular}




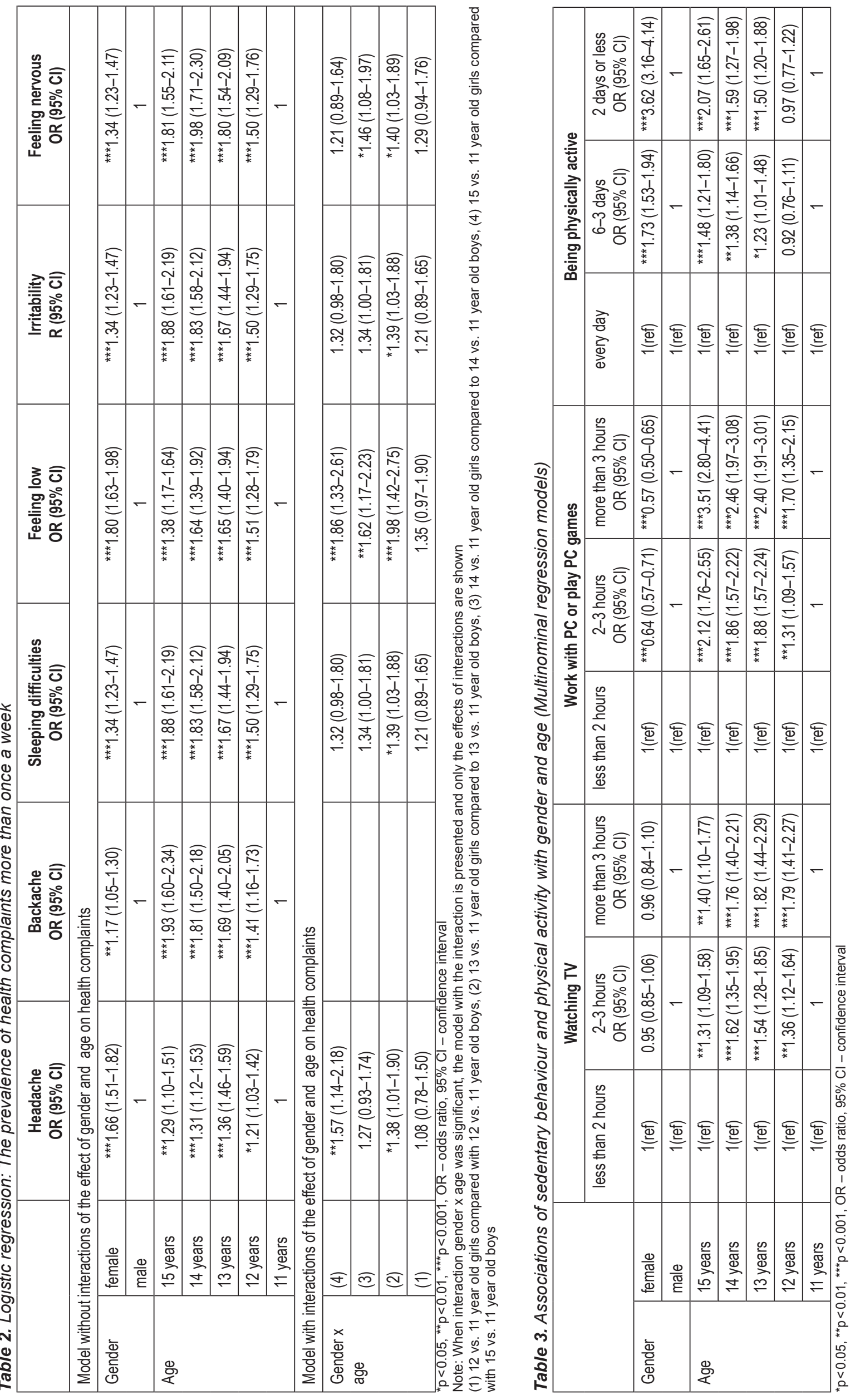


feeling nervous, sleeping difficulties, and feeling dizzy (11). Responses for frequency were on a 5-point scale: rarely or never; about every month; about every week; more than once a week; and about every day. Responses for specific health complaints were dichotomized into those who suffer with health complaints every week and more, and those who experienced them less than every week $(5,30)$.

\section{Statistical Analyses}

In the first step descriptive statistics were used for the studied variables. The association of age and gender (independent variables) with selected health complaints (dependent variables) were analysed using a logistic regression model. Boys and 11 year olds were the reference groups. The chance to report each selected health complaint more than once a week was estimated in separate binary logistic models. Interaction of the association of age and gender on the chance of reporting health complaints were then subsequently explored. When interaction gender $\mathrm{x}$ age was significant, the model with the interaction is presented and only the effects of interactions are shown. Similar procedure was used to estimate the associations between age, gender and screen-based behaviour (watching TV, working with PC or playing PC games), as well as physical activity. As dependent variables are multinominal (watching TV, computer work or playing PC games, physical activity), multinomial regression models were used. Statistical significance was determined at alpha level 0.05 .

\section{RESULTS}

As can be seen in Table 1, a considerable proportion of schoolaged children suffers selected health complaints every week and more (23\% with backache or sleeping disorders, but over $45 \%$ with irritability or feeling nervous). Moreover, the prevalence of health complaints is significantly higher among girls in comparison with boys, and is higher in older adolescents, particularly among girls as well (Table 2).

For example, the steep increase of reporting feeling low (13, 14 and 15 year olds) and headache (13 and 15 year olds) was confirmed among girls in comparison with boys (Fig. 1, 2).

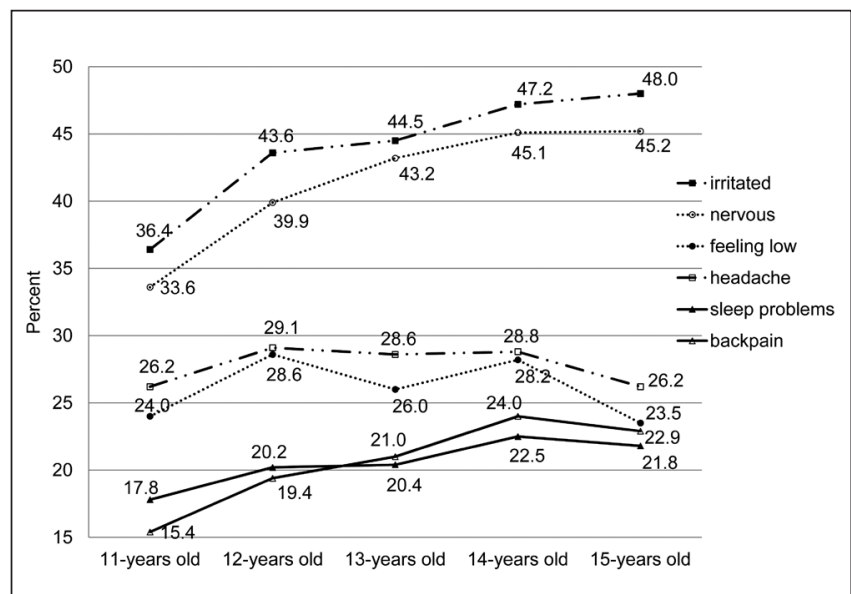

Fig. 1. Prevalence of selected health complains more than once a week in boys (in \%).
On the other hand, only $28 \%$ of respondents watch TV and $36 \%$ work with a PC or play PC games less than 2 hours per day. Only $25 \%$ of respondents reported being physically active every day for at least one hour (Table 1). While the prevalence of those watching TV two and more hours is relatively stable, excessive use of a computer for work or games is higher in older adolescents, particularly among girls (Table 3, Fig. 3 and 4). Nearly half of school-aged respondents reported being physically active 3-6 days per week (Fig. 3). The proportion of those who reported being active every day is lower in older adolescents in comparison with younger ones, particularly among girls.

While girls and boys do not differ in watching TV (2-3 hours, 4 and more hours), boys use computers for work or games significantly more in comparison with girls, while girls are physically active less than 7 days per week, i.e. significantly more often in comparison with boys (Table 3, Fig. 5). The prevalence of excessive computer use or watching TV (2-3 hours, 4 and more hours) as well as insufficient physical activity (less than every day) is significantly higher in older adolescents (Table 3).

\section{DISCUSSION}

The objective of the study was to investigate the prevalence of physical activity, screen-based behaviour as well as subjective health complaints among Slovak school-aged children. Moreover, possible age and gender differences were examined.

The results show that almost half of adolescents suffer from at least one of the psychological complaints every week and more. Moreover, physical complaints seem to be a problem for many of the respondents as well. Having multiple, recurrent subjective health complaints on a weekly basis occur in many other countries (5) and it is also connected with higher levels of other emotional or behavioural problems which significantly impair psychological functioning (31). In addition, higher psychological and somatic symptom loads are associated with frequent computer use $(32,33)$ or with lower levels of physical activity (1). However, De Moor et al. (34) indicate that associations between regular exercise and symptoms of anxiety or depression are not because of causal effects of exercise. A higher occurrence of health complaints, such as headache or feeling low, was observed among older adolescents, especially girls. It might be associated with higher level of

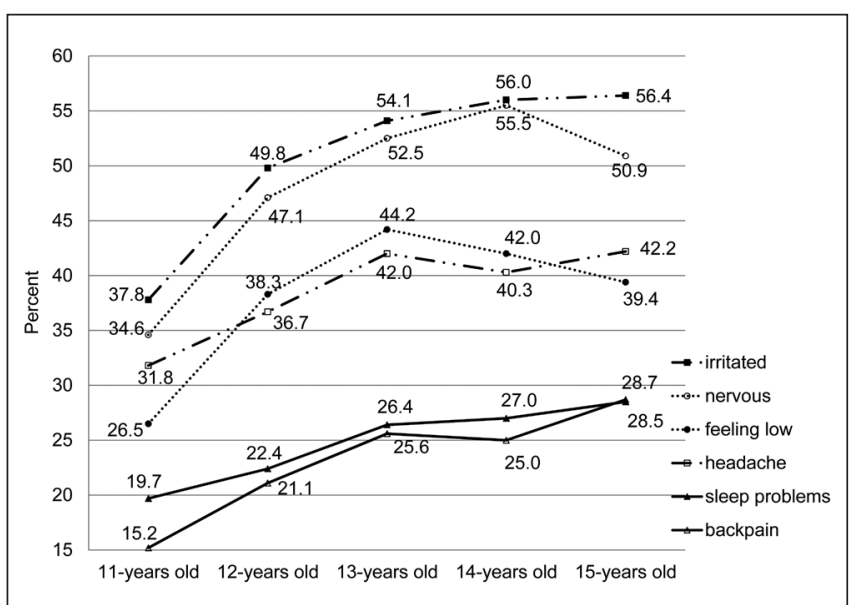

Fig. 2. Prevalence of selected health complains more than once a week in girls (in \%). 


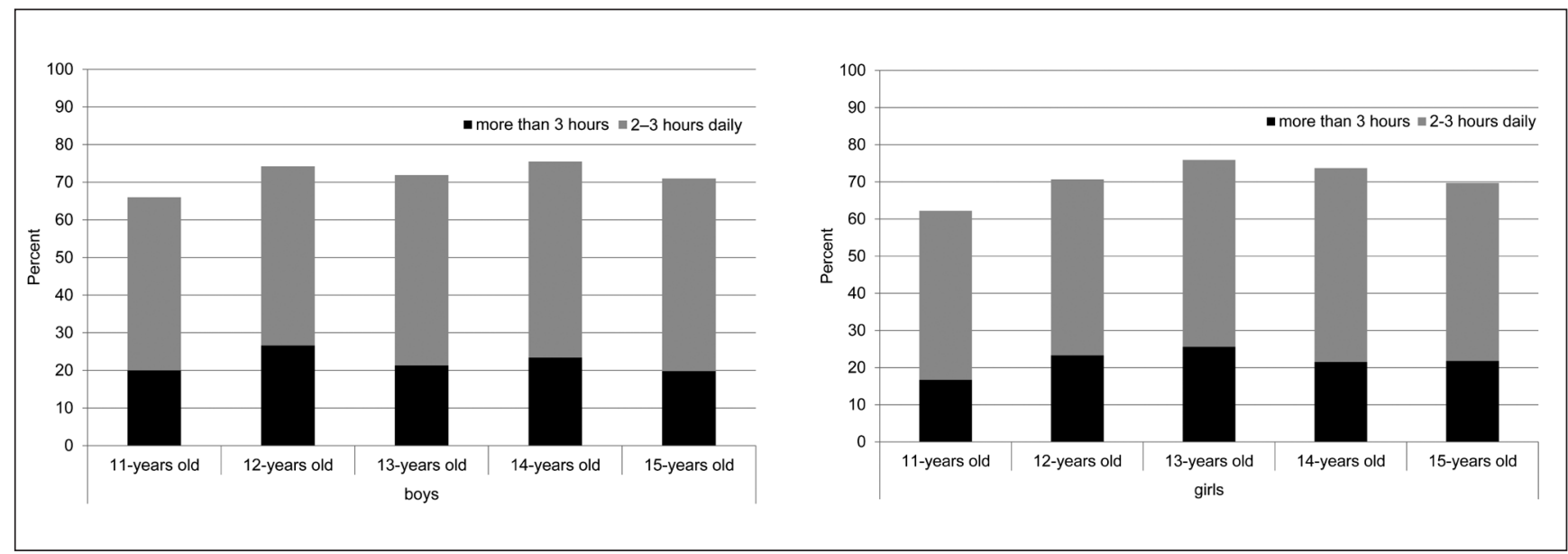

Fig. 3. Prevalence of watching TV by age and gender (in \%).

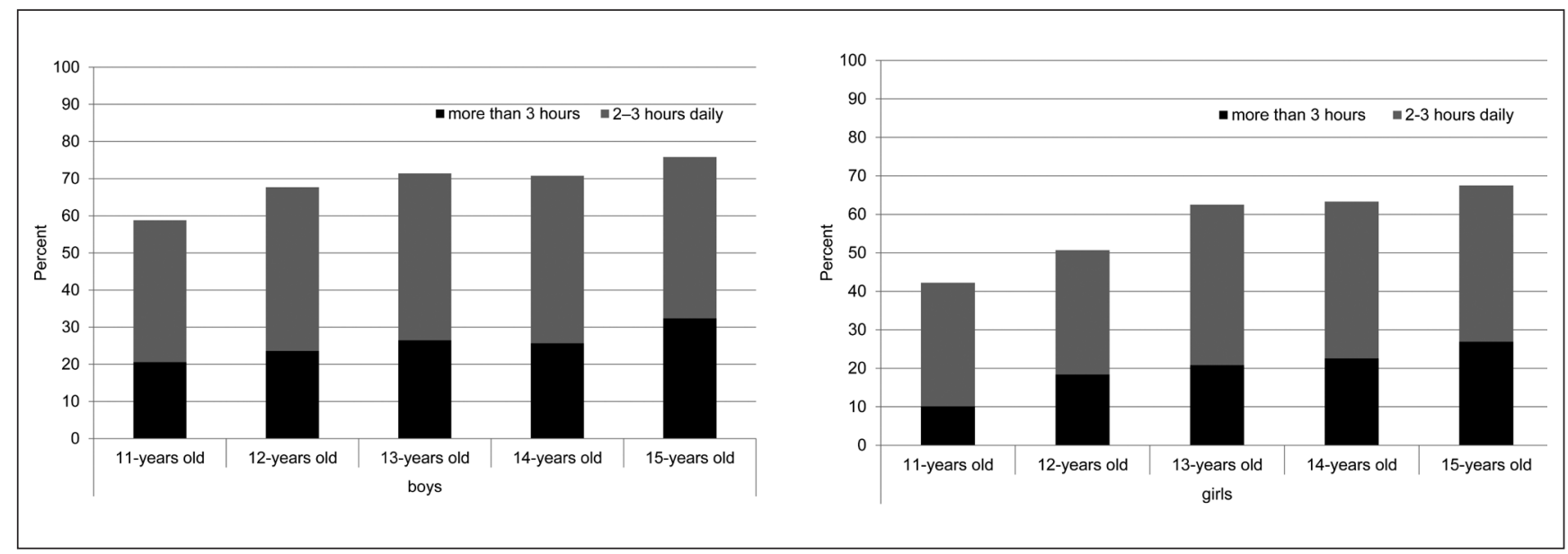

Fig. 4. Prevalence of work with PC or playing PC games by age and gender (in \%).
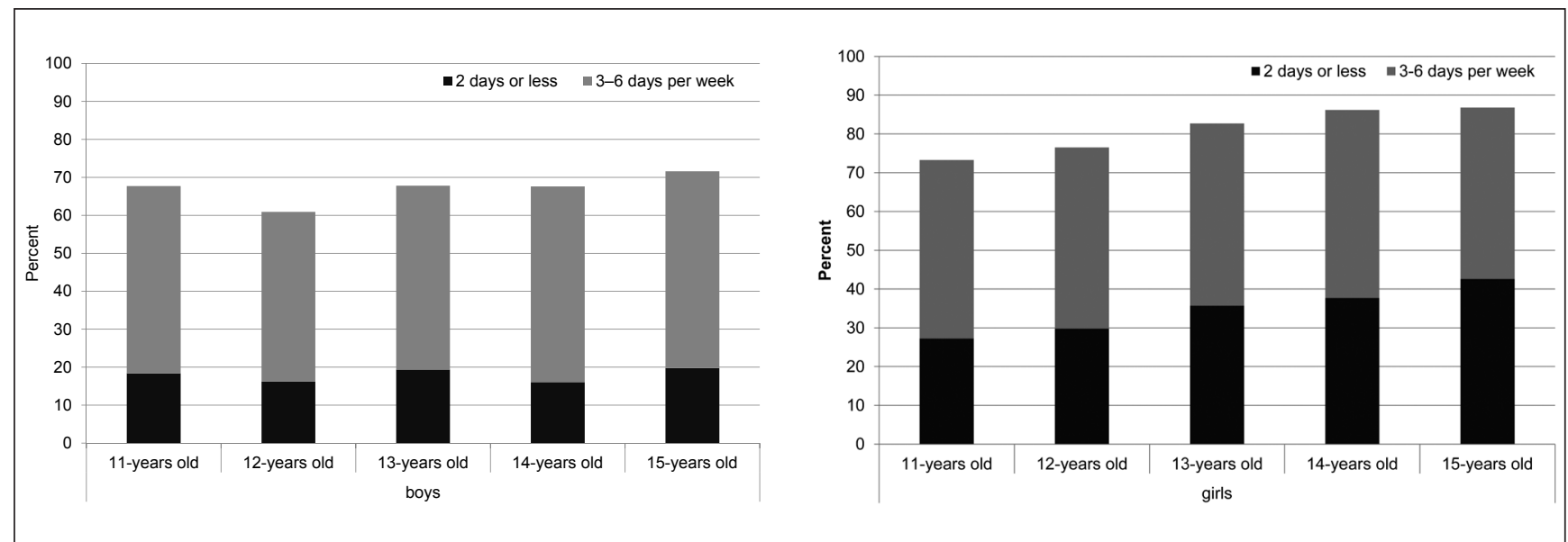

Fig. 5. Prevalence of physical activity by age and gender (in \%).

perceived stress among girls, the finding supported also by the study of Wiklund et al. (35).

Our study also show that nearly half of adolescents exceed the time spending in screen-based activities as recommended, and only one-quarter of them meet the WHO recommendations for physical activity. The high prevalence of screen-based activities as well as insufficient physical activity is also indicated in other studies $(1,36)$. Moreover, the overall level of physical activity is still slightly decreasing in the region (22).

According to our findings, excessive time spent with sedentary screen-based activities increases with age. Similarly, Melkevik et al. (37) reported that older adolescents are more likely to be spending more than 2 hours per day in cumulative screen-time. Taking into account levels of physical activity, results of this 
study are in line with findings reporting that amount of physical activity is decreasing with increasing age (38).

Differences in excessive screen time were observed among girls and boys. While boys use computer more frequently than girls, in case of excessive watching TV, they do not differ, as the TV viewing is the most popular screen activity in leisure time among youth at all (21). Generally, more common activities among boys in comparison with girls are the internet or noninternet computer gaming and other similar computer use (19) which could impact higher amounts of overall screen time among boys (18). In case of amount of physical activity, our study suggests that boys are more involved in regular physical activity regarding the recommendation, the finding also supported in other studies $(39,40)$. The possible reason for this could be that boys seem to be more involved in activities, such as organised sports or plays (41).

This study has several important strengths. The most important strength is the representativeness of our sample of adolescents, and therefore, it is comparable also with existing international data within the HBSC study. However, it has some limitations. The main limitation is that for the measurement of physical activity and screen-based behaviour were used only self-reported data. Some studies indicate that self-reported tools were unable to accurately estimate time spent on an activity, but they may rank individuals accurately $(42,43)$. On the other hand, the accuracy of the accelerometer is dependent on the type of activity and the adherence of the respondents to wearing the accelerometer properly (44-46). Neither the questionnaire nor objective measurements, such as using an accelerometer or pedometer, is a gold standard for measuring physical activity or screen-based behaviour, and validation studies are needed to estimate possible bias. Another limitation is the cross-sectional design of this study, because of its inability to formulate conclusive statements about the causality of our results. The findings therefore need to be confirmed in longitudinal studies. Moreover, in our study electronic devices like smart phones or tablets, which can be also combined for example with physical activities or outdoor/indoor use, were not included despite of their extensive use in adolescents' everyday life. Therefore, the issue of smart phones deserves further study.

\section{CONCLUSION}

In conclusion, the number of adolescents, who use the new communication and information technology, is steeply increasing as well as the number of adolescents who suffer health complaints every week at least. On the other hand, the number of adolescents, who are engaged in physical activity as possible way of compensating, is still low. Moreover, it seems that age and gender are associated with higher or lower prevalence of screen-based activities, physical activity as well as health complaints. Further research and deeper analysing level of physical activity or relation between each screen activities might provide useful information for making effective strategies or interventions, including better education or promotion of healthy living.

\section{Acknowledgements}

This work was supported by the Slovak Research and Development Agency under contract no. APVV-0032-11 and by the Scientific Grant
Agency of the Ministry of Education, Science, Research and Sport of the Slovak Republic and the Slovak Academy of Sciences, reg. no. 1/0895/14.

\section{Ethical Recommendations}

The study was approved by the Ethics Committee of the Faculty of Science at P. J. Šafárik University in Košice.

\section{Conflict of Interest}

None declared

\section{REFERENCES}

1. Iannotti RJ, Kogan MD, Janssen I, Boyce WF. Patterns of adolescent physical activity, screen-based media use, and positive and negative health indicators in the U.S. and Canada. J Adolesc Health. 2009 May;44(5):4939.

2. Smith L, Louw Q, Crous L, Grimmer-Somers K. Prevalence of neck pain and headaches: impact of computer use and other associative factors. Cephalalgia. 2009 Feb;29(2):250-7.

3. Torsheim T, Eriksson L, Schnohr CW, Hansen F, Bjarnason T, Välimaa R. Screen-based activities and physical complaints among adolescents from the Nordic countries. BMC Public Health. 2010 Jun 9;10:324. doi: 10.1186/1471-2458-10-324.

4. Costigan SA, Barnett L, Plotnikoff RC, Lubans DR. The health indicators associated with screen-based sedentary behavior among adolescent girls: a systematic review. J Adolesc Health. 2013 Apr;52(4):382-92.

5. Currie C, Zanotti C, Morgan A, Currie D, de Looze M, Roberts CH, et al., editors. Social determinants of health and well-being among young people. Health Behaviour in School-aged Children (HBSC) study: international report from the 2009/10 survey. Health Policy for Children and Adolescents, No. 6. Copenhagen: WHO Regional Office for Europe; 2012.

6. Biddle SJ, Gorely T, Marshall SJ, Cameron N. The prevalence of sedentary behavior and physical activity in leisure time: a study of Scottish adolescents using ecological momentary assessment. Prev Med. 2009 Feb;48(2):151-5.

7. Galán I, Boix R, Medrano MJ, Ramos P, Rivera F, Pastor-Barriuso R, et al. Physical activity and self-reported health status among adolescents: a cross-sectional population-based study. BMJ Open. 2013 May 14;3(5). pii: e002644. doi: 10.1136/bmjopen-2013-002644.

8. Dumith SC, Gigante DP, Domingues MR, Kohl HW 3rd. Physical activity change during adolescence: a systematic review and a pooled analysis. Int J Epidemiol. 2011 Jun;40(3):685-98.

9. Hallal PC, Andersen LB, Bull FC, Guthold R, Haskell W, Ekelund U; Lancet Physical Activity Series Working Group. Global physical activity levels: surveillance progress, pitfalls, and prospects. Lancet. $2012 \mathrm{Jul}$ 21;380(9838):247-57.

10. Lazzeri G, Azzolini E, Pammolli A, De Wet DR, Giacchi MV. Correlation between physical activity and sedentary behavior with healthy and unhealthy behaviors in Italy and Tuscan region: a cross sectional study. J Prev Med Hyg. 2013 Mar;54(1):41-8.

11. Iannotti RJ, Janssen I, Haug E, Kololo H, Annaheim B, Borraccino A; HBSC Physical Activity Focus Group. Interrelationships of adolescent physical activity, screen-based sedentary behaviour, and social and psychological health. Int J Public Health. 2009 Sep;54(Suppl 2):191-8.

12. Pate RR, Stevens J, Webber LS, Dowda M, Murray DM, Young DR, et al. Age-related change in physical activity in adolescent girls. J Adolesc Health. 2009 Mar;44(3):275-82.

13. Paananen MV, Auvinen JP, Taimela SP, Tammelin TH, Kantomaa MT, Ebeling HE, et al. Psychosocial, mechanical, and metabolic factors in adolescents' musculoskeletal pain in multiple locations: a cross-sectional study. Eur J Pain. 2010 Apr;14(4):395-401.

14. Nader PR, Bradley RH, Houts RM, McRitchie SL, O'Brien M. Moderateto-vigorous physical activity from ages 9 to 15 years. JAMA. $2008 \mathrm{Jul}$ 16;300(3):295-305.

15. Ravens-Sieberer U, Torsheim T, Hetland J, Vollebergh W, Cavallo F, Jericek H, et al.; HBSC Positive Health Focus Group. Subjective health, symptom load and quality of life of children and adolescents in Europe. Int J Public Health. 2009 Sep;54(Suppl 2):151-9. 
16. Petersen S, Hägglöf BL, Bergström EI. Impaired health-related quality of life in children with recurrent pain. Pediatrics. 2009 Oct;124(4):e759-67.

17. Haraldstad K, Sørum R, Eide H, Natvig GK, Helseth S. Pain in children and adolescents: prevalence, impact on daily life, and parents' perception, a school survey. Scand J Caring Sci. 2011 Mar;25(1):27-36.

18. Yang F, Helgason AR, Sigfusdottir ID, Kristjansson AL. Electronic screen use and mental well-being of 10-12-year-old children. Eur J Public Health. 2013 Jun;23(3):492-8.

19. Finne E, Bucksch J, Lampert T, Kolip P. Physical activity and screen-based media use: cross-sectional associations with health-related quality of life and the role of body satisfaction in a representative sample of German adolescents. Health Psychol Behav Med. 2013 Jan 1;1(1):15-30.

20. Guinhouya BC, Samouda H, de Beaufort C. Level of physical activity among children and adolescents in Europe: a review of physical activity assessed objectively by accelerometry. Public Health. 2013 Apr;127(4):301-11.

21. Sigmundová D, Sigmund E, Hamrik Z, Kalman M. Trends of overweight and obesity, physical activity and sedentary behaviour in Czech schoolchildren: HBSC study. Eur J Public Health. 2014 Apr;24(2):210-5.

22. Hamar P, Biddle S, Soós I, Takács B, Huszár A. The prevalence of sedentary behaviours and physical activity in Hungarian youth. Eur J Public Health. 2010 Feb;20(1):85-90.

23. Livingstone S, Haddon L. EU Kids Online: final report. London: EU Kids Online; 2009.

24. Petronyte G, Zaborskis A. The influence of individual and regional factors on association between leisure time physical activity and psychological complaints among adolescents in Europe. Cent Eur J Public Health. 2009 Dec;17(4):215-9.

25. World Health Organization. Global recommendations on physical activity for health. Geneva: WHO; 2010.

26. Biddle SJ, Gorely T, Pearson N, Bull FC. An assessment of self-reported physical activity instruments in young people for population surveillance: Project ALPHA. Int J Behav Nutr Phys Act. 2011 Jan 2;8:1. doi: 10.1186/1479-5868-8-1.

27. Liu Y, Wang M, Tynjälä J, Lv Y, Villberg J, Zhang Z, et al. Test-retest reliability of selected items of Health Behaviour in School-aged Children (HBSC) survey questionnaire in Beijing, China. BMC Med Res Methodol. 2010 Aug 10;10:73. doi: 10.1186/1471-2288-10-73.

28. Ridgers ND, Timperio A, Crawford D, Salmon J. Validity of a brief self-report instrument for assessing compliance with physical activity guidelines amongst adolescents. J Sci Med Sport. 2012 Mar;15(2):136-41.

29. American Academy of Pediatrics, Committee on Public Education. Children, adolescents, and television. Pediatrics. 2001;107(2):423-6.

30. Currie C, Griebler R, Inchley J, Theunissen A, Molcho M, Samdal O, et al., editors. Health Behaviour in School-aged Children (HBSC) study protocol: background, methodology and mandatory items for the 2009/10 survey. Vienna \& Edinburgh: CAHRU \& LBIHPR; 2010.

31. Petanidou D, Giannakopoulos G, Tzavara C, Dimitrakaki C, Kolaitis G, Tountas Y. Adolescents' multiple, recurrent subjective health complaints: investigating associations with emotional/behavioural difficulties in a cross-sectional, school-based study. Child Adolesc Psychiatry Ment Health. 2014 Jan 24;8(1):3. doi: 10.1186/1753-2000-8-3.

32. Nuutinen T, Roos E, Ray C, Villberg J, Välimaa R, Rasmussen M, et al. Computer use, sleep duration and health symptoms: a cross-sectional study of 15-year olds in three countries. Int J Public Health. 2014 Aug;59(4):619-28.
33. Brindova D, Veselska ZD, Klein D, Hamrik Z, Sigmundova D, van Dijk $\mathrm{JP}$, et al. Is the association between screen-based behaviour and health complaints among adolescents moderated by physical activity? Int $\mathrm{J}$ Public Health. 2015 Feb;60(2):139-45.

34. De Moor MH, Boomsma DI, Stubbe JH, Willemsen G, de Geus EJ. Testing causality in the association between regular exercise and symptoms of anxiety and depression. Arch Gen Psychiatry. 2008 Aug;65(8):897-905.

35. Wiklund M, Malmgren-Olsson EB, Ohman A, Bergström E, FjellmanWiklund A. Subjective health complaints in older adolescents are related to perceived stress, anxiety and gender - a cross-sectional school study in Northern Sweden. BMC Public Health. 2012 Nov 16;12:993. doi: 10.1186/1471-2458-12-993.

36. de Moraes AC, Guerra PH, Menezes PR. The worldwide prevalence of insufficient physical activity in adolescents; a systematic review. Nutr Hosp. 2013 May-Jun;28(3):575-84.

37. Melkevik O, Torsheim T, Iannotti RJ, Wold B. Is spending time in screenbased sedentary behaviors associated with less physical activity: a cross national investigation. Int J Behav Nutr Phys Act. 2010 May 21;7:46. doi: 10.1186/1479-5868-7-46.

38. Marques A, da Costa FC. Levels of physical activity of urban adolescents according to age and gender. Int J Sports Sci. 2013;3(1):23-7.

39. Lang C, Brand S, Feldmeth AK, Holsboer-Trachsler E, Pühse U, Gerber M. Increased self-reported and objectively assessed physical activity predict sleep quality among adolescents. Physiol Behav. 2013 Aug $15 ; 120: 46-53$.

40. Kopcakova J, Dankulincova Veselska Z, Madarasova Geckova A, van Dijk JP, Reijneveld SA. Is being a boy and feeling fat a barrier for physical activity? The association between body image, gender and physical activity among adolescents. Int J Environ Res Public Health. 2014 Oct 27;11(11):11167-76.

41. Olds T, Wake M, Patton G, Ridley K, Waters E, Williams J, et al. How do school-day activity patterns differ with age and gender across adolescence? J Adolesc Health. 2009 Jan;44(1):64-72.

42. Bobakova D, Hamrik Z, Badura P, Sigmundova D, Nalecz H, Kalman M. Test-retest reliability of selected physical activity and sedentary behaviour HBSC items in the Czech Republic, Slovakia and Poland. Int J Public Health. 2015 Jan;60(1):59-67.

43. Corder K, van Sluijs EM, Wright A, Whincup P, Wareham NJ, Ekelund U. Is it possible to assess free-living physical activity and energy expenditure in young people by self-report? Am J Clin Nutr. 2009 Mar;89(3):862-70.

44. Slootmaker SM, Schuit AJ, Chinapaw MJ, Seidell JC, van Mechelen W. Disagreement in physical activity assessed by accelerometer and selfreport in subgroups of age, gender, education and weight status. Int J Behav Nutr Phys Act. 2009 Mar 25;6:17. doi: 10.1186/1479-5868-6-17.

45. Baquet G, Stratton G, Van Praagh E, Berthoin S. Improving physical activity assessment in prepubertal children with high-frequency accelerometry monitoring: a methodological issue. Prev Med. 2007 Feb;44(2):143-7.

46. Nilsson A, Ekelund U, Yngve A, Sjöström M. Assessing physical activity among children with accelerometers using different time sampling intervals and placements. Pediatr Exerc Sci. 2002;14(1):87-96.

Received November 12, 2014 Accepted in revised form April 24, 2015 